\title{
Metal Music and Mental Health in France
}

\author{
Robin Recours · François Aussaguel · Nick Trujillo
}

\begin{abstract}
Although numerous authors have associated metal music with social problems such as suicide, self-destruction and Satanism, few studies have been undertaken to examine the mental health of fans of heavy metal music. This study attempts to determine if there is a link between mental health and the enjoyment of this type of music in France. The researchers surveyed 333 fans of metal music. Their mental health was evaluated by the Hospital Anxiety and Depression Scale (HADS), a widely used instrument that measures anxiety and depression. The scores of the sample of metal music fans were then compared to the scores that reveal possible, probable, or severe mental disorders. Qualifying variables included age, gender, status, education, motivation and participation in metal music culture. The results indicated that fans of metal music are mainly young adults (median age $=22.67, \mathrm{SD}=5.29$ ) and tend to be male (87.85 percent). As a whole, metal music fans have levels of anxiety and depression that are similar to and lower than levels in the general population. Specifically, $<5$ percent of metal music fans surveyed showed pathological symptoms. Subjects that scored higher levels of anxiety and depression were those that had literary and/or arts backgrounds rather than scientific backgrounds, that wrote metal music lyrics, that consumed alcohol and that engaged in the body modification practice of scarification. This study suggests that opponents of metal music should re-examine the basis for their criticism. More scholarly research is needed to better understand the effects of metal music on fans and on society.
\end{abstract}

\footnotetext{
R. Recours · F. Aussaguel

Université de Montpellier, 34090 Montpellier, France

N. Trujillo

California State University, 6000 J Street, Sacramento, CA 95819, USA

R. Recours $(\bowtie)$

CAPS, EA 4206, UFR STAPS, 700 Avenue du Pic Saint Loup, 34090 Montpellier, France

e-mail: robin.recours@univ-montp1.fr
} 
Keywords Music - Rock metal music - Mental health · Anxiety ·

Depression

\section{Introduction}

Performed by bands with evocative names such as Megadeth, Black Sabbath and Suicidal Tendencies, "metal music" is characterized by references to death, suicide and Satanism. Critics argue that this type of music has negative impacts on the health and well-being of people who listen to it, especially on young fans. Defenders counter that metal music is a form of entertainment similar to horror films and does not have harmful consequences. This study examines the potential relationship of metal music to the mental health of fans.

\section{A Brief History of Metal Music}

Metal music began in the 1960s and 1970s, primarily in the United Kingdom and the United States (see Binder 1993; Campion 2005; Scheel and Westefel 1999; Wass et al. 1988; Weinstein 1991). Although the roots of this music were blues and the first hard rock bands, Cream followed by Led Zeppelin, early metal bands like Black Sabbath, Judas Priest, Iron Maiden and Motorhead radicalized blues and rock ' $n$ roll by incorporating distortion, hard beats and explosive sounds into the music and dark images into the lyrics. Subsequent metal bands fused elements of punk, hip hop and even classical music into their songs with an even harder edge, as in the works of Megadeth, Iron Maiden, The Scorpions and Evanescence. This music gained in popularity with the introduction of new bands with new sounds, as well as with popular films such as Sam Dunn's Metal: A Headbanger's Journey.

Many variations of metal music have been introduced over the last few decades, including "thrash," "death" and "black" metal (see Christe 2007; Hein 2003). Developed in the early 1980s, thrash metal music is known for its fast and aggressive beat and critical lyrics about social issues such as drugs, suicide, globalization and consumption, as illustrated in the work of Anthrax, Metallica and Slayer. Developed in the mid to late 1980s, death metal music is characterized by melodic distortion, harsh guttural vocals and morbid lyrics, as performed by bands such as Death, Morbid Angels and Possessed. Developed in the late 1980s and early 1990s, black metal music is known for its shrieking vocals, experimentation and anti-Christian and Satanic symbolism, as in the music of Barzum, Mayhem and Venom. Metal music continues to evolve into various fragmented forms.

\section{Critics and Defenders of Metal Music}

Critics of metal music argue that it has negative impacts on society, pointing to media accounts about band members and metal music fans who, individually 
and/or in cults, have desecrated graves and churches, engaged in satanic rituals and committed suicide and murder (see Balducci 1994; Bobineau 2004; Domergue 2000; Regimbald 1983). For example, Marilyn Manson, a superstar of metal music, chose his name because of the reference to serial killer Charles Manson, and he has used images of burning crosses and the number 666 in his music and videos. The lead singer from the band Korn was reported to have mental health problems. In the 1990s, the lead singer of the Norwegian band Mayhem, known for throwing animal heads in public, committed suicide, and the guitarist of the band was brutally murdered. The media blamed the "diabolical" nature of the band and of the heavy metal counter culture as being responsible for these deaths (Campion 2005).

Parent groups and government authorities are especially concerned because children and adolescents have easy access to metal music, lyrics, images and cults through Internet Web sites, file sharing, and other means that are not under the control of parents or officials. Not surprisingly, then, the American Academy of Child and Adolescent Psychiatry has recommended that parents pay close attention to children who listen to metal music because of the potential negative effects (see Alessi et al. 1992).

In France, the situation is somewhat unique because, unlike the United States, cults are outlawed by the Constitution. (For example, the Church of Scientology is prohibited in France.) No country in the world has a religious diversity as extensive as that found in the United States. This religious diversity stems in significant part from the First Amendment to the United States Constitution, which guarantees that all Americans have the freedom to practice the religion(s) of their choice. Recent editions of J. Gordon Melton's Encyclopedia of American Religions lists some 2,300 religious groups active in the United States; most of them have at least 2,000 members. In France, 172 religious groups are officially registered. French officials are particularly concerned about Satanic cults related to metal music. In fact, some black metal music as well as earlier forms have been described as "Catholic rock" because of its images of sin, ghosts and, of course, the devil. As French journalist Robert Belleret (2007) put it with respect to metal music, "It is on the Internet that today the Devil spins its web" (p. 3). Thus, the French government's Interministral Mission of Vigilance and Struggle against the Influence of Cults (La Mivilude 2004) has warned parents to limit their children's exposure to metal music and their access to Internet sites associated with this music. Some Catholic groups have also protested during metal music concerts and festivals, such as Slayer's 2006 concert in Paris and the Hellfest Festival.

In opposition to these critics are various members of metal music fan clubs and musicians who argue that listeners of metal music can distinguish between fiction and reality and that the rituals associated with metal music concerts are fantasies that rarely have serious consequences to the health of the participants. In addition, these groups say that the impact of metal music may be weaker in France because the majority of lyrics are in English, even for French bands. Thus, fans and musicians of metal music believe that the criticism of reporters, politicians and other opponents is unfounded. 
Given the controversy surrounding metal music, we were interested in determining if there is a link between the immersion in metal music culture and the mental health of the individuals who participate. Is an individual who listens to metal music more likely to have serious mental health problems? These are empirical questions, and they form the basis of this study.

\section{Variables and Research Questions}

Generally speaking, we agree with Satcher et al. (2007), who define mental health as "the successful performance of mental function, resulting in productive activities, fulfilling relationships, the ability to adapt to change, and successful coping with adversity" (p. 2540). Although there are several dimensions of mental health, we chose to focus on the anxiety and depression of metal music fans because of their exposure to images of death, suicide and Satanism in this music and culture.

\section{Dependent Variables}

\section{Anxiety and Depression}

The two dependent variables in the study were anxiety and depression. Conceptually, anxiety is defined as a feeling of apprehension and fear characterized by physical symptoms such as sweating and palpitations and/or feelings of stress, restlessness and tension. Depression is defined as a more serious illness that affects the physical and emotional well-being of a person and may be characterized by symptoms such as loss of appetite and sleep, feelings of despair and possible suicidal tendencies, negative thoughts and the notion of the uselessness of life. We wondered if fans of metal music subjected to its dark symbolism would exhibit greater levels of anxiety and depression.

\section{Independent Variables}

Metal music fans differ according to their preferences for musical styles, the type of clothing they wear, their age, and many other factors (Mombelet 2003). Accordingly, we took into account variables that we believed might mediate the anxiety and depression of fans of metal music.

\section{Age, Number of Years as a Fan and Musical Preference}

Metal music has already had three generations of musicians and listeners, and we do not know if the first generation of metal music fans shares a common culture with more recent generations. Thus, we identified as independent variables the age of the participant, the number of years the participant has identified with metal music culture and the type of metal music preferred (thrash, death, black). 


\section{Gender}

In general, males tend to score higher on scales that measure sensation-seeking (Zuckerman 1971). Inasmuch as metal music is a leisure activity that is associated with high levels of stimulation (e.g., loud music, very physical dancing), we identified gender as an independent variable.

\section{Employment Status, Education and Field of Study}

Some studies have shown that employment status and education are strong markers of human behavior (Baudelot and Establet 1971; Berthelot 1983; Boudon 1973). We broke employment status into three categories based on Bourdieu (1984): "high" (factory owners, managers, professionals), "medium" (teachers, business employees, office workers) and "low" (factory workers, welfare recipients). In addition, an individual's field of study (e.g., literary and arts, scientific, economic, professional, technical) has been shown to influence one's perspective as well (Dubet 1991). We believed that each of these factors might contribute to the mental health of metal music fans, and thus, we identified them as independent variables.

\section{Body Modification and Concert Attendance and Participation}

Metal music fans and performers create a unique subculture through various symbolic images and performances (Canetti 1966; Walser 1993). For example, many fans of metal music engage in body modification practices, ranging from discreet tattooing to severe scarring. In addition, fans differ in terms of the number of concerts they attend each year and the type of performances they engage in at concerts. For example, the most common forms of participation include "pogoing" (pushing and jumping into each other), "slamming" (passing a person overhead), "stage diving" (leaping from the stage into the crowd), "moshing" (hitting or smashing into each other with high impact) and "Bravehearting" (when fans separate into two lines and rush at each other, as in the film Braveheart). For this reason, we identified as independent variables types of body modification and concert attendance and participation.

\section{Motivation for Participation}

Metal music fans attend concerts and participate in metal music rituals for different reasons, such as to listen to their favorite bands, to enjoy the atmosphere of concerts and to drink and/or use drugs, among others. Thus, we included motivation as an independent variable.

\section{Research Questions}

R1 Do metal music fans in France exhibit great levels of anxiety and depression?

R2 What variables mediate the levels of anxiety and depression for metal music fans? 


\section{Methods}

\section{Instrument}

We assessed a group of metal fans' mental health with the Hospital Anxiety and Depression Scale (HADS). This scale was developed by Zigmond and Snaith (1983) to detect anxiety and depressive states, the most common form of psychological disturbance in hospitals and in the general population. The HADS instrument has been used widely by researchers to study various populations (e.g., patients with cancer and heart problems, medical students, the elderly).

The HADS instrument consists of 14 items, each using a 4-point scale from 0 to 3 , and it is simple to use. In addition, because of the subtle nature of the questions, the subject taking the instrument is usually unaware that it is measuring anxiety or depression. This was a distinct advantage in this study because we believe that fans of metal music are sensitive to the prejudice against them and, therefore, might be nervous or defensive in taking a questionnaire about their mental health.

The HADS instrument is considered to be effective in terms of factor structure, intercorrelation, homogeneity, and reliability (see Herrmann 1997; Mykletun et al. 2001). In most countries where this scale has been administered, factor analysis has yielded a model of two factors, although a third factor has emerged in some studies of populations with good health (Brandberg et al. 1992). After orthogonal (varimax) rotation, factor correlations with the noncorresponding subscales are low $(<0.40)$ indicating that the subscales can be conceptualized as two theoretically independent dimensions. Most studies have shown satisfactory item-total correlations within the two subscales. Internal consistency has been acceptable, with Cronbach's $\alpha$ between 0.80 and 0.93 for anxiety and between 0.81 and 0.90 for depression. Retest reliability has shown a high correlation $(r>0.80)$ after up to 2 weeks, although this correlation decreases after longer time intervals. Generally, the scores of the HADS instrument are better distributed (in terms of normality) than the State-Trait Anxiety Inventory (STAI) and the Beck Depression Inventory (BDI). Due to its simplicity and neutrality, most studies have had response levels between 95 and 100 percent, even in sensitive populations (see Herrmann 1997).

Although it is not used to make definitive diagnoses, the HADS instrument can reveal pathological levels of anxiety and depression. To identify subjects likely to be anxious or depressed, the ordinal scale score must be dichotomized at a particular cutoff point. There is no single, generally accepted cutoff score for the HADS. In their original study, Zigmond and Snaith recommended two cutoff scores for both subscales: 7/8 for possible and 10/11 for probable anxiety or depression. In subsequent studies, the same authors proposed a cutoff score of 14 for "severe" mental disorders (Snaith and Zigmond 1994).

In this study, we followed research on the quality of life in France (Boyer et al. 2006) and chose the conservative cutoff score of 11 for each dimension (anxiety score $\geq 11$, probable anxiety; depression score $\geq 11$, probable depression). A study using the same scale and the same cutoffs (Herrmann et al. 1995) showed that an abnormal HADS score was observed in 10 percent of subjects with good mental health $(n=152)$ and 71 percent with psychiatric patients $(n=69)$. In another study 
with people suffering from depression $(n=2669)$, 91 percent were found to have abnormal HADS scores (Friedman et al. 2001).

We used all 14 items of the HADS instrument, translated and validated in French (Razavi et al. 1989). The scale was divided into two subscales with alternate items: anxiety (items 1, 3, 5, 7, 9, 11, 13) and depression (items 2, 4, 6, 8, 10, 12, 14). In addition, we included items to measure each of the independent variables, including age, gender, employment status, education and field of study, body modification, motivation and number of and type of participation at metal concerts.

The survey was composed of three parts: the first dealt with the demographic characteristics of the subjects, the second dealt with their motivation and participation in metal music and the third was composed of 14 items from the HADS instrument.

\section{Pretest of Instrument}

We expected that adolescents and young adults would comprise a majority of our sample of metal music fans. Therefore, we tested the instrument on a group of 20 adolescents in school to make sure that all the questions were easily understood and accepted by a young population. After administration of the questionnaire, subjects were interviewed in order to isolate and modify any problematic items or questions. This new version was then administered to the sample.

\section{Sample}

We needed a sample of metal music fans to complete the HADS instrument. Our first inclination was to administer the instrument at places where fans gather: at concerts or at practice areas. However, we believed that group dynamics or concert euphoria might bias the results. We also considered administering the survey to fans of metal music that we could identify on the streets (through clothing such as teeshirts with morbid themes and studded necklaces) but realized that we would miss metal music fans who do not/did not wear such attire.

Thus, we administered the instrument via the Internet by posting it on the largest French Internet forums dedicated to metal music. This decision had two distinct advantages. First, it permitted us to contact metal music fans individually, as participation in Internet forums is usually conducted by individuals in front of a computer screen at home or in a cybercafé. As such, the results are not biased by group dynamics. Second, using the Internet permitted us to reach fans with high levels of interest in metal music, because those who are most interested are more likely to visit and participate in Internet Web sites and forums devoted to metal music. We believed that a sample of metal music fans who are most devoted to this type of music was the best sample to assess the potential effects of this music.

We posted the instrument on the 10 Internet sites for a two-week period. Questionnaires with incoherent or incomplete responses were removed from the analyses. This could eliminate some of the ill, we concede, as the most depressed would be least likely to fill out a questionnaire. 
We conducted a factor analysis to verify the validity of the scale. We used multiple linear regression analysis and ANOVA to asses the effects of the independent variables. Unless otherwise indicated, significance levels for all analyses was the $p<0.05$ level.

\section{Results}

Among the 333 metal enthusiasts who responded to the survey, 9 gave partial or incoherent responses. We eliminated these individuals from the study before conducting the analyses, which resulted in a 97.3 percent response rate.

\section{Descriptive Results}

The sample consisted of 282 males ( 87.85 percent) and 39 females (12.15 percent). The mean age was 22.67 years old $(\mathrm{SD}=5.29)$. Approximately one-half $(49.53$ percent) were students and 41.74 percent were employed (8.73 percent were both employed and students). The sample was diversified with respect to other variables (see Table 1).

The average number of years in metal music culture was 9.22 years $(\mathrm{SD}=5.77$, maximum $=30$ years). The average number of concerts each year was 15.65. However, there was a large disparity between the participants: $S D=18.60$, maximum $=100$ concerts. A little more than one-third of the respondents $(35.20$ percent) had permanent body modifications (e.g., tatoos, piercings, scarifications) whereas 5.30 percent had a combination of two types of body modifications (e.g., tatoo and piercing).

The ritual most widely performed during concerts (Table 2) was "pogo" $(M=1.86, \mathrm{SD}=0.69)$, whereas the least widely performed was "stage diving" $(M=1.21, \mathrm{SD}=0.47)$. Almost half of the sample (44.55 percent) belonged to a metal rock band or club. Respondents expressed varying preferences for different types of metal music, including "death metal" (37.69 percent), "black metal" (22.74 percent) and "thrash metal" (18.07 percent).

The motivations for metal concert participation were also diverse (see Fig. 1). In the survey, respondents were given the option to select multiple motivations for attending concerts. The majority of the reasons for attending concerts included to listen to music they enjoy (95.93 percent), for the ambiance (84.62 percent), to party (66.97 percent) and/or to unwind (55.66 percent); a smaller percentage of reasons included to drink a lot (33.94 percent), while a very small percentage included to take drugs (4.98 percent), to sell drugs (2.72 percent) and/or to fight (0.91 percent).

Factor Analysis

Factor analysis yielded a three-dimensional structure that explained 47.60 percent of the variance. A three-dimensional structure was not unexpected since we had no 
Table 1 Descriptive results

a The English term "piercing" in France refers not to traditional ear piercings of many women and men, but to piercings in nontraditional areas such as the nose, tongue, eyelid, and nipple

\begin{tabular}{|c|c|c|}
\hline & $n$ & \\
\hline Men & 282 & $87.85 \%$ \\
\hline Women & 39 & $12.15 \%$ \\
\hline Mean age, year & & $22.67(\mathrm{SD}=5.29)$ \\
\hline \multicolumn{3}{|l|}{ Grade level } \\
\hline Brevet (middle school) & 64 & $19.94 \%$ \\
\hline Baccalauréat (high school) & 92 & $28.66 \%$ \\
\hline License & 92 & $28.66 \%$ \\
\hline Master & 61 & $19.00 \%$ \\
\hline Educational background & 159 & $49.53 \%$ \\
\hline Scientific & 54 & $33.96 \%$ \\
\hline Literary and arts & 40 & $25.16 \%$ \\
\hline Economic & 21 & $13.21 \%$ \\
\hline Other & 44 & $27.67 \%$ \\
\hline Employment & 134 & $41.74 \%$ \\
\hline High status & 42 & $28.19 \%$ \\
\hline Middle status & 56 & $37.58 \%$ \\
\hline Low status & 34 & $22.82 \%$ \\
\hline Other & 17 & $11.41 \%$ \\
\hline Mean no. of years in the culture & & $9.22(\mathrm{SD}=5.77)$ \\
\hline Mean no. of concerts each year & & $15.65(\mathrm{SD}=18.60)$ \\
\hline Belong to a band/association/label & 143 & $44.55 \%$ \\
\hline "Death metal" style & 121 & $37.69 \%$ \\
\hline "Black metal" style & 73 & $22.74 \%$ \\
\hline "Thrash metal" style & 58 & $18.07 \%$ \\
\hline Body modification & 113 & $35.2 \%$ \\
\hline Tatoos & 62 & $19.31 \%$ \\
\hline Piercings $^{\mathrm{a}}$ & 58 & $18.07 \%$ \\
\hline Scarifications & 10 & $3.12 \%$ \\
\hline
\end{tabular}

Table 2 Rituals at concerts: respondents scored their participation on a Likert scale from 1 ("never") to 3 ("often")

\begin{tabular}{|c|c|c|}
\hline & Mean (SD) & Short description \\
\hline Pogoing & $1.86(0.69)$ & Pushing or smashing into each other, jumping all over the place \\
\hline Slamming & $1.33(0.55)$ & $\begin{array}{l}\text { The process in which a person is passed overhead from person to } \\
\text { person during a concert }\end{array}$ \\
\hline Stage diving & $1.21(0.47)$ & The act of leaping from a concert stage onto the crowd below \\
\hline Moshing & $1.38(0.62)$ & An activity involving high-impact body contact (hitting, smashing) \\
\hline Bravehearting & $1.43(0.64)$ & $\begin{array}{l}\text { Pushing or smashing into each other (when music stops, dancers } \\
\text { separate into two opposite camps; when music resumes, dancers } \\
\text { in the two camps rush at each other) }\end{array}$ \\
\hline
\end{tabular}




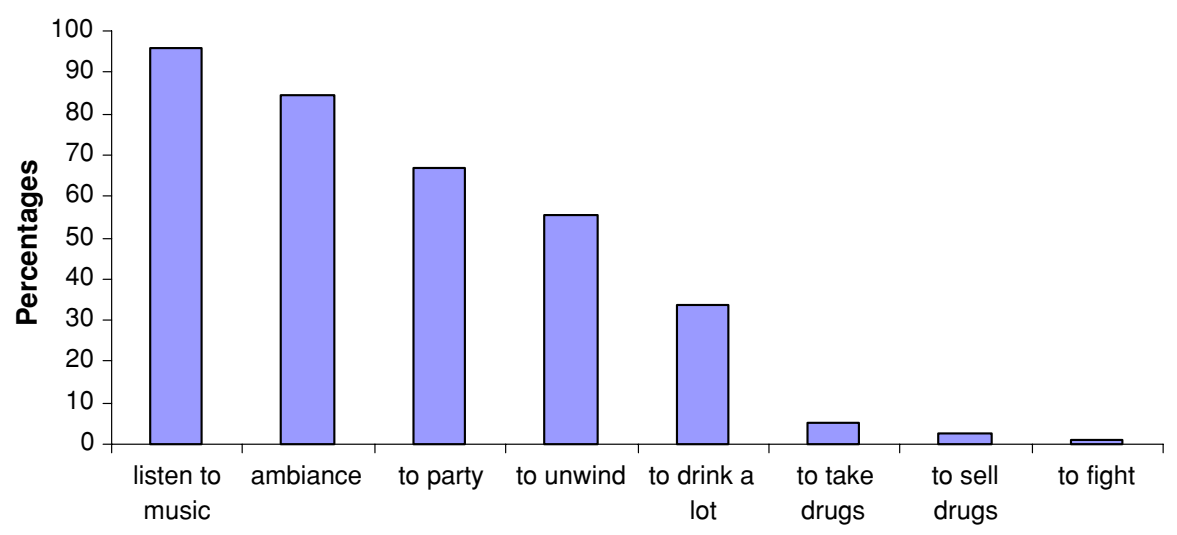

Fig. 1 Motivations for metal concert attendance/participation

Table 3 HADS factor analysis (after two factors for orthogonal rotation were predetermined)

\begin{tabular}{lcc}
\hline & Factor 1 (anxiety) & Factor 2 (depression) \\
\hline Mean & 7.26 & 3.76 \\
SD & 3.44 & 2.91 \\
Variance explained & $27.55 \%$ & $11.17 \%$ \\
Eigenvalue & 3.86 & 1.56 \\
$\alpha$ & 0.70 & 0.67 \\
\hline
\end{tabular}

evidence a priori that our sample would have high levels of anxiety or depression. Following Friedman et al. (2001), we performed an orthogonal rotation (see Table 3) to test the two-factor model (depression and anxiety). These two factors derived from the HADS factor analysis explained 38.71 percent of the variance (anxiety explaining 27.55 percent of the variance, eigenvalue $=3.86$; depression capturing 11.17 percent of the variance, eigenvalue $=1.56$ ). The reliability factors using Cronbach's $\alpha$ were 0.70 for anxiety and 0.67 for depression.

In general, the results indicated that the respondents had low levels of anxiety and depression. The average scores (anxiety, $M=7.26, \mathrm{SD}=3.44$; depression, $M=3.76$, $\mathrm{SD}=2.91$ ) were far below the cutoff levels used to determine mental disorders (score $\geq 11$ ). However, as in all populations, there were some individuals who scored above this cutoff; specifically 15.58 percent of the subjects had a high probability of anxiety (score $\geq 11$ ) and 3.43 percent of them had a high probability of depression (score $\geq 11$ ). So-called "severe" subjects (as measured by Zigmond and Snaith) constituted $<5$ percent for anxiety $(n=16)$ and $<1$ percent for depression $(n=2)$.

\section{Multiple Regression Analyses}

The multiple regression analyses revealed that gender, age, number of concerts per year, preferred musical style and body modification practices of tattooing and piercing had no link to mental health, in terms of either anxiety or depression. 
On the other hand, these same analyses revealed that grade level and employment status had links to mental health. The results indicated that as the grade level of the respondents goes up, the anxiety level of respondents goes down. The least anxious respondents were those who had a master's degree, whereas the most anxious respondents were those with only a middle school or a high school degree (NewmanKeuls, $p<0.05)$. Students coming from literary and arts backgrounds were found to be more anxious than those of scientific backgrounds $[t(91)=2.36, p<0.05]$. The results also showed that the lower the employment status, the higher the level of depression and of anxiety. Lower classes of workers were more anxious and depressed than members of the middle class (Newman-Keuls, $p<0.05$ ), whereas middle-class individuals were more anxious and depressed than upper-class individuals $(p<0.05)$.

The analyses also revealed that writing lyrics for a band, consuming high levels of alcohol during concerts and the specific body modification practice of scarification have links to mental health. Specifically, fans of metal music who write song lyrics scored significantly higher than others on the subscales of anxiety $[t(320)=2.75, p<0.05]$ and depression $[t(320)=2.46, p<0.05]$. Metal music enthusiasts who drink a lot of alcohol at concerts scored significantly higher than the others on the subscale of anxiety $[t(210)=3.24, p<0.05]$ but not on the subscale of depression. In addition, metal music fans who had scarifications scored significantly higher than the others on the depression subscale $[t(320)=2.38$, $p<0.05$ ] but not on the anxiety subscale. However, the higher scores on the subscales of depression or anxiety do not necessarily mean that these metal music fans are abnormally anxious or depressed because the scores were below the danger cutoff (score $\geq 11$ ).

A multiple linear regression analysis (see Table 4) for concert rituals showed that "stage diving," "moshing" and "Bravehearting" were not significantly linked to mental health. This same analysis showed, however, that individuals who practiced "pogoing" were significantly less anxious than others and individuals who practiced "slamming" were significantly more anxious than the others. Nevertheless, the $R^{2}$ remained very low, meaning that if there is a significant relation between these kinds of rituals and mental health, the relation is very weak.

Table 4 Multiple linear regression analysis for rituals in concerts

\begin{tabular}{|c|c|c|c|c|c|c|}
\hline & \multicolumn{3}{|l|}{ Anxiety } & \multicolumn{3}{|c|}{ Depression } \\
\hline & $\beta$ & B & $t(293)$ & $\beta$ & B & $t(293)$ \\
\hline Intersect & & 6.564 & 9.327 & & 3.482 & 5.612 \\
\hline Pogoing & $-0.205^{* *}$ & -1.023 & -3.036 & -0.072 & -0.308 & -1.035 \\
\hline Slamming & $0.208 * *$ & 1.341 & 2.612 & 0.067 & 0.372 & 0.821 \\
\hline Stage diving & 0.067 & 0.505 & 0.860 & 0.067 & 0.436 & 0.841 \\
\hline Moshing & 0.034 & 0.191 & 0.529 & 0.002 & 0.011 & 0.034 \\
\hline \multirow[t]{3}{*}{ Bravehearting } & -0.001 & -0.005 & -0.013 & -0.029 & -0.133 & -0.405 \\
\hline & \multicolumn{3}{|c|}{$R=0.25, R^{2}=0.06$} & \multicolumn{3}{|c|}{$R=0.11, R^{2}=0.13$} \\
\hline & \multicolumn{3}{|c|}{$F(5,293)=4.04 * *$} & \multicolumn{3}{|c|}{$F(5,293)=0.75^{*}$} \\
\hline
\end{tabular}

Note: $* p<0.05 ; * * p<0.01$ 


\section{Discussion}

Our sample consisted of mostly male subjects, ages 13-44 that came from a wide range of education and employment statuses. In this regard, although the sample may appear to be biased toward males, it is very representative of the culture of metal music as described by the scientific literature in France (Mombelet 2003) and in other Western countries (Arnett 1996; Walser 1993). In addition, because this sample consisted of individuals who were more likely to be serious fans of metal music, they were more likely to be influenced by this music and culture.

The use of the HADS instrument proved to be effective for this sample in that 97.3 percent of respondents filled it out completely. However, the factor analysis of the instrument yielded three factors instead of two (anxiety and depression), although three factors also emerged in previous studies of populations in good health (Brandberg et al. 1992).

The results indicate that fans of metal music are in good health with respect to anxiety and depression. The percentage of anxious and depressed individuals in the sample was low, and very few were judged to be severely pathological. These results indicate that, contrary to critics who suggest that images of death and destruction in metal music have harmful consequences, the mental health of fans of this type of music is generally good.

However, this study provided evidence that certain variables have effects on the mental health of metal music fans. For example, with respect to variables external to metal music culture, the study showed some links between the educational and employment status of metal music fans and their mental health. We believe, however, that individuals who are less educated and less established in their career will feel more anxiety and depression in general, regardless of the type of music they listen to (see Santelmann 2002). These individuals have less qualified/skilled jobs and may see themselves as valued less in social life than those in more qualified/skilled professions (see Baudrillard 1970; Bourdieu 1984).

With respect to the influence of a literary and arts background on anxiety scores, some researchers suggest that literary and arts schools and universities are sometimes perceived as less professional than scientific and engineering schools (Dubet 1991), so any associated levels of anxiety could come from the difficulty (real or presumed) experienced by of individuals with literary or arts backgrounds who must enter the working world. It is necessary to conduct further research to determine if this result would be found in a larger and more heterogenous sample.

With respect to the influence of gender, the small sample size of females prevented a meaningful analysis. It is unclear if female fans of metal music are more like other fans (both female and male) or like other women in general. Additional research on this question should be undertaken.

Concerning variables internal to metal music culture, the results show that several factors had little or no influence on mental health, including preferred style of music, number of concerts attended each year and whether fans have tatoos or piercings. However, other factors did seem to influence the anxiety and depression of metal music fans, including whether they wrote metal music lyrics, consumed lots of alcohol during concerts and engaged in scarification. With respect to writing 
songs, it would be interesting to determine whether writing metal music songs increases anxiety or if being anxious motivates one to write metal music songs. After all, history is filled with writers who spent time in psychiatric hospitals, prompting Kaufmann (1990:194) to suggest a "circular" relationship between writing and sanity. The connection between alcohol use at concerts and anxiety is fraught with similar ambiguity: it may be that people who are anxious will drink more, regardless of the type of music they prefer. However, previous studies have found links between the use of alcohol and depression (Deykin et al. 1987), and our results did not confirm this connection with our sample of metal music fans.

Finally, the results show a link between depression and scarification, the most extreme form of body modification. Because the lesions are self-inflicted, scarification is usually considered to be an act of self-mutilation. Some studies have found that, of all the middle and high school students needing to see the school nurse, 11.30 percent of girls and 6.60 percent of boys admit to having voluntarily injured themselves (e.g., cuts and burns) in the past 12 months (Choquet et al. 2001). Among the students that admitted to having tried to commit suicide, almost three-quarters of them (72.60 percent) reported cutting or burning themselves, whereas only 15.90 percent of those who have not tried to commit suicide reported similar cuts and burns. Clearly, if scarification is an indicator of suicide risk, it also may be an indicator of anxiety and depression (Conwell et al. 1996). The results of the present study confirm this finding, as we found a link between scarifications and depression. However, our results also indicated that, although fans of metal music who engage in scarification may have a higher depression score than those who do not engage in this body modification practice, this score remains well below the danger cutoff.

Concerning the dance rituals, the results revealed links between practicing "pogoing" or "slamming" and mental health. It appears that metal music enthusiasts who show signs of more anxiety participate in the more collective "slamming," whereas metal music enthusiasts who show less anxiety participate in the more individual "pogoing." It may be that the individual nature of "pogoing" is enacted by those with a stronger sense of individuality and, thus, with less anxiety about themselves. In contrast, the more collective "slamming," in which participants are passed above the crowd, may be a way for those with more anxiety to learn to trust others and decrease their anxiety. More research could be done to examine these dynamics.

\section{Conclusion}

Considering band names such as Suicidal Tendencies, Megadeth and Black Sabbath, and references to death, suicide and self-destruction, it is not surprising that critics of metal music portray it as sick, dangerous, psychopathic and even Satanic, and argue that it has harmful consequences to fans (see Balducci 1994; Domergue 2000; Regimbald 1983). This study, however, showed that fans of metal music in France exhibit overall low levels of anxiety and depression. 
We believe it is quite possible that metal music fans' fascination with images of death may have positive consequences. Many scholars concur that images and open discussions of death have decreased over the past several decades in most Western societies (see Baudry 1991; Campbell 1991; Le Breton 1991; Leroi-Gourhan 1988). The mass media in these cultures emphasize youth and fitness rather than aging and death, especially in entertainment and advertising images. Previous generations of people were far more likely to die at home in front of family and close friends, but now the end of life usually occurs behind the closed doors of hospitals and nursing homes, where the sights, sounds and smells of death are camouflaged. Most of us are not taught how to die or how to care for someone who is dying. Many people now do not even talk of death but, instead, use euphemisms such as "passed away" and "lost."

Obviously, the mass media present many images of death to various audiences. Horror and slasher films offer ghastly and grotesque images of death and destruction, but these images are presented as a form of entertainment and escape rather than reality. In addition, television news and crime shows are often graphic in their presentation of dead and decomposing bodies, some of which may have been tortured or mutilated, though these cases are considered to be deviant, illegal and outside the norm.

In contrast, metal music may be a form of entertainment, but it presents images of death and destruction as more typical occurrences that are not outside the norm. Indeed, the "death" and "black" forms of metal music, in particular, portray murder and suicide as everyday events that happen to everyday people, even if such portrayals may be thought to be macabre by some. As the band Metallica concluded in their 1984 hit "Fade to Black," "Death greets me warm, now I will just say goodbye."

Kubler-Ross and other scholars who have studied death and dying argue that people who confront death more openly and directly are more likely to deal with it in a more healthy manner and to be more comfortable with their own mortality (see Dickinson et al. 2000; Kubler-Ross 1973; Vande Berg and Trujillo 2008). Perhaps the constant exposure to symbols of death helps fans of metal music to feel less anxiety and depression and, in some ways, to have better mental health than members of the general population, who do not confront death and mortality so openly. Additional research could shed more light on this interesting possibility.

Acknowledgments The authors would like to thank Professor Marika Moisseeff (Psychiatry) and Professor Véronique Campion-Vincent (Folklorism) for their many useful discussions and incisive comments on the first and subsequent drafts of the manuscript. They also would like to thank Frédéric Rocheron and Jean Griffet for their support, Thomas McQuaid and Pamela Ruttum for their translation and the two anonymous reviewers for their significant insights and suggestions for improvement.

\section{References}

Alessi, Norman, Milton Huang, P. James, J. Yang, and N. Chowhan

1992 The Influence of Music and Rock Videos. Facts for Families (No. 40). Available at: Psychiatry Star, American Academy of Child and Adolescent Psychiatry, Facts for Families Index. 
Arnett, Jeffrey Jensen

1996 Metalheads: Heavy Metal Music and Adolescent Alienation. Boulder, CO: Westview Press.

Balducci, Corrado

1994 Adorateurs du diable et rock satanique. Paris: Téqui.

Baudelot, Christian, and Roger Establet

1971 L'Ecole capitaliste en France. Paris: Maspero.

Baudrillard, Jean

1970 La société de consommation, ses mythes, ses structures. Paris: Denoël.

Baudry, Patrick

1991 Le corps extrême. Approche sociologique des conduites à risque. Paris: L'Harmattan.

Belleret, Robert

2007 Le diable en toile de fond. Le Monde 27(06): 3.

Berthelot, Jean-Michel

1983 Le piège scolaire. Paris: PUF.

Binder, Amy

1993 Constructing Racial Rhetoric: Media Depictions of Harm in Heavy Metal and Rap Music. American Sociological Review 58(6): 753-767.

Bobineau, Olivier

2004 Liturgie. In Notions. Paris: Encyclopedia Universalis.

Boudon, Raymond

1973 L'inégalité des chances dans les sociétés industrielles. Paris: Armand Colin.

Bourdieu, Pierre

1984 Distinction: A Social Critique of the Judgement of Taste. Cambridge, MA: Harvard University Press.

Boyer, François, Jean-Luc Novella, Jean-Michel Coulon, Frédéric Delmer, Isabella Morrone, N. Lemoussu, V. Bombart, A. Calmus, J.-Y. Cornu, V. Dulieu, and Jean-Claude Etienne

2006 Les aidants familiaux des personnes myopathes: liaisons entre charge de soins, qualité de vie et santé mentale. Annales de réadaptation et de médecine physique 49: 16-22.

Brandberg, Yvonne, Christina Bolund, Valgerdur Sigurdardottir, Per-Olow Sjödén, and Marianne Sullivan

1992 Anxiety and Depressive Symptoms at Different Stages of Malignant Melanoma. PsychoOncology 1: 71-78.

Campbell, Joseph

1991 Puissance du mythe. Paris: J'ai lu.

Campion, Chris

2005 In the face of death. Available at: http://observer.guardian.co.uk.

Canetti, Elias

1966 Masse et puissance. Paris: Gallimard.

Choquet, Marie, Xavier Pommereau, and Christophe Lagadic

2001 Les élèves à l'infirmerie scolaire: identification et orientation des jeunes à haut risque suicidaire. Enquête réalisée auprès de 21 établissements scolaires du département de la Gironde, à la demande de la Direction Générale de la Santé. Paris: INSERM.

Christe, Ian

2007 Sound of the Beast: L'histoire définitive du Heavy Metal. Paris: Flammarion.

Conwell, Yeates, Paul R. Duberstein, Christopher Cox, John H. Forbes Herrmann, T. Nicholas, and Eric

D. Caine

1996 Relationships of Age and Axis I Diagnoses in Victims of Completed Suicide: A Psychological Autopsy Study. American Journal of Psychiatry 153: 1001-1008.

Deykin, Eva Y., Janice C. Levy, and Victoria Wells

1987 Adolescent Depression, Alcohol and Drug Abuse. American Journal of Public Health 77(2): 178-182.

Dickinson, Donna, Malcolm Johnson, and Jeanne Sampson Katz

2000 Death, Dying and Bereavement. London: Sage.

Domergue, Benoît

2000 Culture barock et gothic flamboyant, un écho surgi des abîmes: la musique extrême. Paris: Guilbert.

Dubet, François

1991 Les lycéens. Paris: Seuil. 
Friedman, Serge, Jean-Claude Samuelian, Sylvie Lancrenon, Christian Even, and Pierre Chiarelli

2001 Three-Dimensional Structure of the Hospital Anxiety and Depression Scale in a Large French Primary Care Population Suffering from Major Depression. Psychiatry Research 104: 247-257. Hein, Fabien

2003 Hard Rock, Heavy Metal, Metal. Histoire, cultures et pratiquants. Paris: Mélanie Séteun/IRMA. Herrmann, Christoph

1997 International Experiences with the Hospital Anxiety and Depression Scale: A Review of Validation Data and Clinical Results. Journal of Psychosomatic Research 42(1): 17-41.

Herrmann, Christoph, Ullrich Buss, and R. Philip Snaith

1995 HADS-D: Hospital Anxiety and Depression Scale-Deutsche Version; Ein Fragebogen zur Erfassung von Angst und Depressivität in der somatischen Medizin. Bern: Verlag Hans Huber.

Kaufmann, Vincent

1990 L’équivoque épistolaire. Paris: Minuit.

Kubler-Ross, Elizabeth

1973 On Death and Dying. Routledge,

Le Breton, David

1991 Passion du risque. Paris: Métailié.

Leroi-Gourhan, André

1988 Dictionnaire de la préhistoire. Paris: PUF.

Mission interministérielle de vigilance et de lutte contre les dérives sectaires

2004 Rapport au Premier Ministre. Paris: Miviludes.

Mombelet, Alexis

2003 Les concerts de musique metal: approche anthropologique. Mémoire de Master. ClermontFerrand: Université Blaise Pascal.

Mykletun, Arnstein, Eystein Stordal, and Alv Dahl

2001 Hospital Anxiety and Depression (HAD) Scale: Factor Structure, Item Analyses and Internal Consistency in a Large Population. British Journal of Psychiatry 179: 540-544.

Razavi, Darius, Nicole Delvaux, Christine Farvacques, and E. Robaye

1989 Validation de la version française du HADS dans une population de patients cancéreux hospitalisés. Revue de Psychologie Appliquée 39: 295-308.

Regimbald, Jean-Paul

1983 Le Rock n'Roll, viol de la conscience par les messages subliminaux. Sherbrooke: Editions St-Raphaël.

Santelmann, Paul

2002 Formation professionnelle et emplois non qualifiés. Droit Social 4: 437-444.

Satcher, David, Sharon Friel, and Ruth Bell

2007 Natural and Manmade Disasters and Mental Health. Journal of the American Medical Association 298: 2540-2542.

Scheel, Karen R., and Joh S. Westefel

1999 Heavy Metal Music and Adolescent Suicidality: An Empirical Investigation. Adolescence 34: 253-273.

Snaith, R. Philip, and Anthony S. Zigmond

1994 HADS: Hospital Anxiety and Depression Scale. Windsor: NFER Nelson.

Vande Berg, Leah, and Nick Trujillo

2008 Cancer and Death: A Love Story in Two Voices. Cresskill, NJ: Hampton Press.

Walser, Robert

1993 Running with the Devil. Power, Gender and Madness in Heavy Metal Music. Hanover, NH: Wesleyan University Press.

Wass, Hannelore, Jana L. Raup, Karen Cerullo, Linda G. Martel, Laura A. Mingione, and Anna M. Sperring

1988 Adolescents and Destructive Themes in Rock Music: A Follow-up. Omega 23: 199-206.

Weinstein, Deena

1991 Heavy Metal: A Cultural Sociology. New York: Lexington Books.

Zigmond, Anthony S., and R. Philip Snaith

1983 The Hospital Anxiety and Depression Scale. Acta Psychiatria Scandinavica 67: 361-370.

Zuckerman, Marvin

1971 Dimensions of Sensation Seeking. Journal of Consulting and Clinical Psychology 36: 45-52. 